\title{
COMPARISON OF INDUCTION THERAPY USING ANTI-THYMOCYTE GLOBULIN AND USING BASILIXIMAB FOR LIVE DONOR KIDNEY TRANSPLANT RECIPIENTS: A SINGLE-CENTER, PROSPECTIVE, COHORT STUDY
}

\author{
SANKET PATEL ${ }^{1 *}$, KALPESH GOHEL ${ }^{2}$, PATEL BG ${ }^{3}$ \\ ${ }^{1}$ Department of Clinical Pharmacy, Ramanbhai Patel College of Pharmacy, Charotar University of Science \& Technology, Changa - 388421 , \\ Gujarat, India. ${ }^{2}$ Muljibhai Patel Urological Hospital, Nadiad, Gujarat, India. ${ }^{3}$ Charotar University of Science \& Technology, Changa - 388421 , \\ Gujarat, India. Email: sanketgpate103@gmail.com \\ Received: 14 July 2016, Revised and Accepted: 23 July 2016
}

\section{ABSTRACT}

Objective: Acute rejections (ARs) have a negative impact on long-term graft survival and are the major predictor of chronic rejection. Induction therapy is used to reduce AR and prevent delayed graft function (DGF). Anti-thymocyte globulin (ATG) and basiliximab are mainly used for this purpose. In this prospective, cohort study, we analyzed and compared the safety and efficacy of ATG and basiliximab in induction therapy for live donor kidney transplant recipients.

Methods: Graft survival, AR-free survival, renal function, DGF, and tolerability were compared in patients who underwent live donor transplantation between January 2014 and August 2014 at Muljibhai Patel Urological Hospital, Nadiad, Gujarat, India.

Results and Discussion: A total of 85 live donor kidney transplant recipients who enrolled were followed up for 12 months. The incidence of AR was greater in the basiliximab group, as compared with the ATG group $(25.6 \%$ vs. $7.1 \%, \mathrm{p}<0.05)$. The incidence of antibody-treated AR was also greater $(18.6 \%$ vs. $2.4 \%, \mathrm{p}<0.05)$. Patient survival rate and graft survival rate were $95.2 \%$ and $92.9 \%$ in the ATG group, respectively, compared with $90.4 \%$ and $90.7 \%$ in the basiliximab group, respectively. The incidence of adverse events was higher in the ATG group compared with the basiliximab group (71.4\% vs. $48.3 \%, \mathrm{p}<0.05)$.

Conclusion: The incidence of AR and antibody-treated AR was significantly higher in the basiliximab group than in the ATG cohort. However, ATG was associated with the significantly higher incidence of adverse events and leukopenia than basiliximab. Both the strategies were achieved similar patient and graft survival.

Keywords: Anti-thymocyte globulin, Basiliximab, Induction therapy, Biopsy-proven acute rejection, Live donor transplantation.

(C) 2016 The Authors. Published by Innovare Academic Sciences Pvt Ltd. This is an open access article under the CC BY license (http://creativecommons. org/licenses/by/4. 0/) DOI: http://dx.doi.org/10.22159/ajpcr.2016.v9i6.14099

\section{INTRODUCTION}

Renal transplantation is the treatment of choice for patients with endstage renal disease, to improve both qualities of life and life expectancy. Controlling the alloimmune reaction is imperative for successful renal transplantation. The occurrence of delayed graft function (DGF) and acute rejections (AR) during the early post-transplantation period may have a negative effect on graft survival [1,2]. Patients with DGF have a greater risk of AR, and graft survival is better in those who do not have DGF or AR compared with those who have either or both [2]. DGF has been defined as the need for dialysis within the first week after transplantation and/or a serum creatinine level, in the absence of dialysis, $250 \mathrm{mmol} / \mathrm{L}$ or more at day 10 of post-transplantation [3].

The activation and subsequent proliferation of resting $\mathrm{T}$ lymphocytes is an essential factor in the development of AR episodes [4]. Therefore, drugs that affect either T-cell activation or proliferation are used to prevent AR and DGF. Such drugs are known as induction agents. Induction therapy is administered at the time of transplantation to reduce the incidence of AR or to prevent DGF. Long-term graft survival is improved by induction therapy [1,5]. At present, $90 \%$ of renal transplant recipients is treated with induction therapy. Two types of induction agents are used as (1) lymphocytes-depleting agents and (2) interleukin-2 (IL-2) receptor antagonists (non-lymphocytedepleting agent). Basiliximab or daclizumab, an IL-2 receptor antagonist, is used in $36.8 \%$ of renal allograft recipients, and T-celldepleting agents such as anti-thymocyte globulin (ATG) (lymphocytedepleting agent) are used in $55.7 \%$ of all renal allograft recipients. The percentage of recipients receiving no induction therapy is $10.4 \%$ [6].
ATG, rabbit-derived lymphocyte-depleting polyclonal antibody, is administered intravenously through a series of divided doses or a bolus dose. The importance of the IL-2/IL-2R pathway in the proliferation of T-lymphocytes, together with the selective expression of CD25 (the alpha chain of the IL-2 receptor subunit) on activated lymphocytes, suggests that CD25 inhibition can reduce the incidence of acute graft rejection [7]. Basiliximab, a chimeric monoclonal antibody, bind to the alpha chain of the IL-2 receptor (IL-2R alpha) with an affinity equal to that of IL-2, and hence, it is a potent inhibitor of IL-2-mediated T-cell proliferation [8]. It is administered as prophylactically in two divided doses of $20 \mathrm{mg}$ on day 0 and day 4 of post-transplantation.

Every so often, profound and excessive immunosuppression is achieved with induction agent, which may sometimes increase the risk of infection-bacterial (Pneumocystis pneumonia and Mycobacterium tuberculosis) or viral mainly cytomegalovirus (CMV) disease and posttransplant lymphoproliferative disorder (PTLD) [9-12]. The current study was carried out to analyze and compare the clinical outcomes in terms of graft function, number of rejections, infections, and hospital admissions, in live renal allograft recipients who had received basiliximab and ATG induction therapy with a triple-drug regimen (tacrolimus, mycophenolate, and steroids), in an Indian population, over a period of 12 months.

The objective of the study was to evaluate the efficacy, safety, and tolerability of basiliximab, and ATG when these are administered in combination with a triple - immunosuppressive regimen of tacrolimus, steroids, and mycophenolate mofetil (MMF) in live donor transplant recipients. The safety and tolerability of basiliximab and 
ATG were assessed by comparing the incidences in the two treatment groups of adverse events, infections (bacterial, viral, and fungal), and development of malignancies. The safety and tolerability were also evaluated by comparing the duration of post-transplant hospitalization in the two groups.

\section{METHODS}

This was a prospective, observational, cohort study of 1-year with follow-up data analysis. Renal transplant data about patients with live-related and other-than-related (OTR) donors and data about ABOincompatible transplantations performed at Muljibhai Patel Urological Hospitals, Nadiad, Gujarat, India, were collected. ATG or basiliximab had been administered as induction therapy to the patients. Data about patients who had received second grafts were also collected. Ethical approval was obtained from the Institute Ethics Committee of Muljibhai Patel Society for Research in Nephro-Urology, and informed consent was obtained from all the patients. Transplant patient with deceased donors and those who were not administered induction therapy were excluded from the analysis. All the patients had been offered either basiliximab or ATG as induction therapy. Basiliximab was administered in a dose of $20 \mathrm{mg}$ intravenously 2 hrs before transplantation and on day 4 after the operation. Treatment with ATG was initiated intraoperatively before graft reperfusion. The dose of ATG varied from 1.5 to $6 \mathrm{mg} / \mathrm{kg}$ and was administered either as a bolus or as divided doses.

\section{Concomitant therapy}

Throughout the study, in addition to basiliximab or ATG, all patients received a triple immunosuppressive regimen consisting of tacrolimus, steroids, and MMF as maintenance therapy. Pulse methylprednisolone ( $1 \mathrm{~g}$ ) was given intravenously to all patients on day 0 . Oral prednisone was subsequently prescribed, starting at $1.0 \mathrm{mg} / \mathrm{kg}$ and tapered to 7.5-10 mg/d. MMF (2000 mg/day) was administered orally from day 2 in both groups. MMF was continued throughout the study if possible, but the dose was reduced or discontinued in the event of suspected toxicity, according to clinical judgment. Tacrolimus trough levels of 5-10 ng/ml were targeted for the initial 2 months and levels of 3-7 ng/ $\mathrm{ml}$ were targeted thereafter in both groups. All the recipients received prophylaxis for CMV, i.e., oral valganciclovir for 3-6 and for P. pneumonia, i.e., cotrimoxazole for 6-12 months.

\section{Clinical evaluation}

The demographic and baseline data gathered included the age, weight, genders of the recipient and donor, human leukocyte antigen (HLA) mismatch, baseline serum creatinine level, native kidney disease, number of transplantation, and type of living donor (related or OTR) Hemoglobin level, white cell and platelet counts, tacrolimus trough level, and serum creatinine level were recorded at day 0 and 7 and month $1,3,6,9$, and 12 . AR was diagnosed either clinically or through biopsies. AR episodes were treated either with intravenous courses of methylprednisolone (500-1000 mg) or with monoclonal antibodies, depending on the severity of rejection.

\section{Statistical analysis}

Statistical analysis was performed using MedCalc15.4. Categorical variables were summarized as total number and percentages, and continuous variables were summarized as means with standard deviations. Categorical data were compared using Fisher's exact test, and continuous variables were compared using the Mann-Whitney test or the unpaired $t$-test. Kaplan-Meier analysis was conducted for AR-free survival, defined as the period without an acute decline in glomerular filtration due to biopsy-proven AR and graft survival. $\mathrm{p}<0.05$ was considered statistically significant.

\section{RESULTS}

The baseline demographic characteristics of the recipients are presented in Table 1. There were 42 patients in the ATG group and 43 patients in the basiliximab group. In general, the demographics of the two groups were similar, but several high-risk characteristics were more prevalent in the ATG group. The ATG group had a higher proportion of HLA mismatches and OTR donor transplantations compared with the basiliximab cohort. All the 42 patients in the ATG group completed the study except four: Two of them had graft failure, and the other two died during the study period. In the basiliximab group, 37 out of the 43 patients were followed until the end of the study. Four patients could not be followed to the end of the study period due to graft loss, and two could not be followed due to death.

All the patients except six in the basiliximab cohort (86\%) received both the $20 \mathrm{mg}$ doses as intravenous bolus injections at the scheduled times according to the protocol. The second dose was not given to the six patients because of AR; instead, they received ATG injections. Patients in the ATG group received a mean cumulative dose of $177.4 \pm 50 \mathrm{mg}$ (median $175 \mathrm{mg}$ and range $75-275 \mathrm{mg}$ ). The proportion of patients who received the second dose of ATG was $19.04 \%$. The use of maintenance immunosuppressive therapy in the two groups was generally similar. However, at 12 months, a significantly higher number of patients in the basiliximab group (11) than in the ATG group (3) were receiving MMF or enteric-coated mycophenolate sodium ( $26.2 \%$ vs. $6.9 \%$; $=0.0381$ ). The mean daily dose of tacrolimus and mean whole blood trough levels were not different in the two groups. The use of concomitant medication was also comparable in the two groups. The mean duration of hospitalization was 6.6 days in the basiliximab group, compared with 7.9 days in the ATG cohort $(p=0.667)$. Nine patients in the ATG group were hospitalized for 10 days or longer, compared with seven patients in the basiliximab group.

\section{Efficacy}

The values of the efficacy parameters of the two cohorts are presented in Table 2. At 12 months, the patient and graft survival rates were $90.4 \%$ and $90.7 \%$, respectively, in the basiliximab group; in the ATG group, they were $95.2 \%$ and $92.9 \%$, respectively. The total number of biopsy-proven AR episodes was significantly higher in the basiliximab cohort compared with the ATG cohort $(25.6 \%$ vs. $7.1 \%, \mathrm{p}<0.05)$. Antibody-treated AR episodes occurred in eight patients $(18.6 \%)$ of the basiliximab group, compared with one patient $(2.4 \%)$ of the ATG group. The frequency of antibody-treated rejections was significantly higher in the basiliximab group compared with the ATG group $(\mathrm{p}<0.05)$. Eight patients had AR episodes within 1 month of transplantation in the basiliximab group while in the ATG group only two had rejection episodes during the first month of transplantation. 13 patients $(30.2 \%)$ in the basiliximab group had treatment failure (11 AR and 2 graft loss), compared with 5 patients (11.9\%) in the ATG group, 2 of died, with the rest having AR. Kaplan-Meier survival analysis showed ATG was associated with significantly higher AR-free survival than basiliximab (p<0.05; Fig. 1).

\section{Renal function}

DGF is defined as the need for post-operative dialysis and/or a serum creatinine level above $250 \mathrm{mmol} / \mathrm{L}(2.82 \mathrm{mg} / \mathrm{dl})$ at day 10 posttransplant. The incidence of DGF was $11.6 \%(n=8)$ in the basiliximab cohort, and it was $7.1 \%(n=3)$ in the ATG group. Of these, five patients underwent post-operative dialysis ( $n=4$ for basiliximab; $n=1$ for ATG). The other three patients ( $n=1$ for basiliximab, $n=2$ for ATG) did not require dialysis but had slow graft function. Among the patients with DGF, two in the ATG cohort and four in the basiliximab group had rejections. The creatinine clearance level was statistically significant in favor of ATG at week 1 (Table 3). At 12 months, the serum creatinine level was below $1.5 \mathrm{mg} / \mathrm{dl}$ in 29 out of 38 patients in the ATG group and 29 out of 37 patients in the basiliximab group.

\section{Safety}

The most of the patients $(n=30$ in the ATG group and $n=21$ in the basiliximab group) experienced one or more adverse events. The number of patients in the ATG group who had adverse events was greater than the corresponding number of the basiliximab cohort Likewise, the total number of events was also higher in the ATG cohort $(n=52)$ than in the basiliximab group $(n=34)$, with the number 
Table 1: Baseline and demographic characteristics of recipients and donors

\begin{tabular}{|c|c|c|c|}
\hline Characteristics & ATG $(n=42)$ & Basiliximab $(n=43)$ & p value \\
\hline \multicolumn{4}{|l|}{ Recipient } \\
\hline Male/Female & $33 / 9$ & $34 / 9$ & 1.000 \\
\hline Weight & $60.4 \pm 10$ & $56.3 \pm 8.4$ & 0.0926 \\
\hline Mean recipient age (years) & $39.92 \pm 8.33$ & $37.53 \pm 8.39$ & 0.1154 \\
\hline Pre-Txn dialysis (Months) & $10 \pm 7$ & $3.4 \pm 1.9$ & 0.1747 \\
\hline Second transplantation & $5(11.9)$ & $3(7.0)$ & 0.4833 \\
\hline Pre-emptive transplantation & 6 & 8 & 0.7711 \\
\hline Donor's age & $46.6 \pm 10.1$ & $49.8 \pm 8.11$ & 0.1075 \\
\hline Donor's gender male/female & $11 / 31$ & $16 / 27$ & 0.3528 \\
\hline Living other than related & $28(66.7)$ & $4(9.3)$ & $<0.000001^{*}$ \\
\hline \multicolumn{4}{|l|}{ Native kidney disease } \\
\hline DKD & $14(33.3)$ & $10(23.3)$ & 0.0928 \\
\hline CGN & $6(14.3)$ & $6(14)$ & \\
\hline Interstitial nephritis & $2(4.8)$ & $3(7)$ & \\
\hline Polycystic kidney disease & $3(7.1)$ & $3(7)$ & \\
\hline HLA mismatch & $4.14 \pm 1.6$ & $3.6 \pm 1.06$ & 0.0823 \\
\hline Mean lymphocytes cross match (\%) & 4.81 & 3.94 & 0.4449 \\
\hline Mean baseline Serum creatinine (mg/dl) & $3.5 \pm 1.4$ & $4.2 \pm 1.8$ & 1.0000 \\
\hline
\end{tabular}

HLA: Human leukocytes antigen, Txn: Transplantation, Data are expressed as mean values, with plus-minus values as SD, or as numbers, with percentages in parentheses; *Significant, SD: Standard deviation

Table 2: Incidence of efficacy variables during the 12-month post-transplantation period

\begin{tabular}{|c|c|c|c|}
\hline Efficacy variable & $\begin{array}{l}\text { ATG } \\
(n=42)\end{array}$ & $\begin{array}{l}\text { Basiliximab } \\
(n=43)\end{array}$ & p value \\
\hline Biopsy-proven AR & $3(7.1)$ & $11(25.6)$ & $0.0381 *$ \\
\hline $\begin{array}{l}\text { First AR episode treated with } \\
\text { antibody therapy }\end{array}$ & $1(2.4)$ & $8(18.6)$ & $0.0295^{*}$ \\
\hline Graft loss & $3(7.1)$ & $4(9.3)$ & 1.0000 \\
\hline Death & $2(4.8)$ & $2(4.7)$ & 1.0000 \\
\hline Treatment failure & 5 (11.9) & $13(30.2)$ & 0.0616 \\
\hline Delayed graft function & $3(7.1)$ & $5(11.6)$ & 0.7130 \\
\hline Graft survival & $39(92.9)$ & $39(90.7)$ & 1.0000 \\
\hline Patient survival & $40(95.2)$ & $41(90.4)$ & 1.0000 \\
\hline
\end{tabular}

$\mathrm{p}$ value finds by Fisher exact test; treatment failure is defined as AR, graft loss or death whichever occur first. *Statistically significant. ATG: Anti-thymocyte globulin, AR: Acute rejection

Table 3: GFR (mean \pm SD) during 12-month post-transplant period

\begin{tabular}{llll}
\hline Parameters & ATG & Basiliximab & p value \\
\hline Day 0 & $22.2 \pm 19.36$ & $21.83 \pm 9.77$ & 0.7917 \\
Day 7 & $76.12 \pm 31.49$ & $64.90 \pm 23.18$ & $0.0290^{*}$ \\
1 month & $60.35 \pm 26.35$ & $69.58 \pm 18.31$ & 0.0808 \\
3 month & $69.59 \pm 22.85$ & $63.85 \pm 16.82$ & 0.5169 \\
6 month & $69.39 \pm 30.35$ & $66.88 \pm 19.61$ & 0.9712 \\
9 month & $70.94 \pm 32.29$ & $64.51 \pm 16.50$ & 0.6744 \\
12 month & $82.82 \pm 35$ & $71.78 \pm 21.34$ & 0.5391 \\
\hline
\end{tabular}

Mann-Whitney test; *Statistically significant. ATG: Anti-thymocyte globulin,

GFR: Glomerular filtration rate, SD: Standard deviation

of serious adverse events in the ATG cohort being 12 (23.1\%) and $10(29.4 \%)$ in the basiliximab group. The total number of episodes of leukopenia was significantly higher in the ATG group $(n=14)$ than in the basiliximab cohort $(n=6)$. There were three cases of thrombocytopenia in the ATG group while there was no patient with thrombocytopenia in the basiliximab group. No significant hematologic or biochemical abnormalities were seen in the basiliximab group.

A total of 26 patients (61.9\%) in the ATG group had one or more infectious episodes $(n=38)$, whereas there were 18 patients $(41.8 \%)$ in the basiliximab group who had a total of 26 different types of infectious episodes (Table 4). The majority of these infections affected the urinary tract. Six patients in the ATG group and three patients in the basiliximab group had CMV infections. All the patients responded to treatment with either parenteral or oral ganciclovir administration, depending on the severity of the infection. No cases of malignancy either new or recurrent, and in particular, no cases of PTLD were seen in either treatment group during the study period.

\section{DISCUSSION}

Since the introduction of several novel immunosuppressive agents, there is a reduction in the frequency of AR episodes. Nonetheless, $\mathrm{AR}$ is still a major problem in renal transplant recipients, and chronic rejection, in particular, remains undiminished or has even increased [13]. In this context, induction strategies using monoclonal or polyclonal anti-lymphocyte antibodies have an important role to play. Induction therapy is administered to reduce AR and to reduce the use/dose of maintenance therapy and is of particular benefit to highrisk patients (sensitized patients, second-graft recipients, pediatric patients). Mainly, two types of antibodies are used as induction agent (1) polyclonal ATG and (2) IL-2 receptor antagonist (basiliximab and daclizumab). Induction therapy using ATG combined with CsA, MMF, and steroids (17\% vs. $29 \%$ for placebo) [14], or with tacrolimus, azathioprine, and steroids (15.2 vs. $30.4 \%$ with placebo) [15] can reduce the occurrence of acute cellular rejection. Basiliximab acts at a specific site on T-lymphocytes and thus prevents $\mathrm{T}$ cell proliferation. Thus, the additional risk of adverse events is minimal compared with lymphocytes-depleting agents. Basiliximab reduced the incidence of acute graft rejection $[16,17]$. It is well established that ATG reduces AR episodes compared with anti-IL-2 receptor agents. However, it did not improve graft or patient survival.

In the present study population, consistent with the previous findings, the incidence of DGF was similar in the ATG and basiliximab groups [18-20]. Lebranchu et al. observed a higher incidence of treatment failure with a basiliximab group (14\%) than with an ATG group (8\%) [3]. Similarly, in the present study, there was more treatment failure in the basiliximab group than in the ATG group (30.2\% vs. $11.9 \%, \mathrm{p}<0.05)$. However, Brenan and Yang et al. found no difference in their study $[18,20]$

The efficacy and safety of induction therapy administered using ATG and using basiliximab for adult live-donor kidney transplant recipients were compared in this study. 


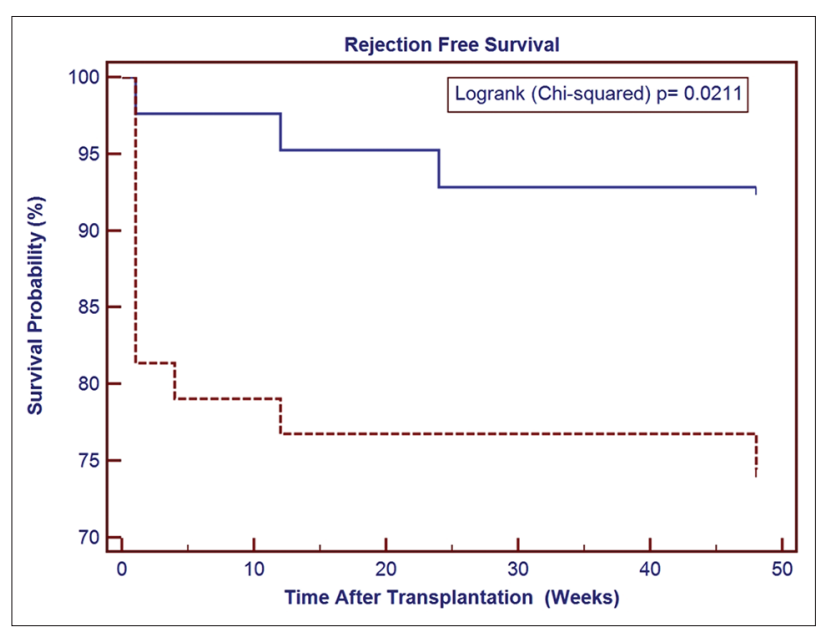

Fig. 1: Kaplan-Meier survival curve for 1-year rejection-free survival in renal transplant recipient using anti-thymocyte globulin and basiliximab

Table 4: Adverse events profile during the 12-month post-transplantation period

\begin{tabular}{llll}
\hline Characteristic & $\begin{array}{l}\text { ATG } \\
(\mathbf{n = 4 2 )}\end{array}$ & $\begin{array}{l}\text { Basiliximab } \\
(\mathbf{n = 4 3 )}\end{array}$ & p value \\
\hline $\begin{array}{l}\text { Patients with one or } \\
\text { more adverse events }\end{array}$ & $30(71.4)$ & $21(48.3)$ & $0.0464^{*}$ \\
$\begin{array}{l}\text { Total number of } \\
\text { adverse events }\end{array}$ & 52 & 34 & \\
$\begin{array}{l}\text { Serious adverse events } \\
\text { Patients with infections }\end{array}$ & $14(33.3)$ & $11(25.6)$ & 0.4816 \\
Total episodes of & $26(61.9)$ & $18(41.8)$ & 0.0836 \\
infection & 38 & 29 & \\
UTI & 14 & 13 & 0.6170 \\
Bacterial infection & 11 & 7 & 0.7833 \\
CMV & 6 & 3 & 0.7212 \\
Viral infection & 3 & 5 & 0.2782 \\
Fungal infection & 4 & 1 & 0.3824 \\
Leukopenia & $14(33.3)$ & $6(14)$ & $0.0431^{*}$ \\
Thrombocytopenia & $3(7.1)$ & 0 & 0.1162 \\
\hline
\end{tabular}

*p value finds by Fisher exact test, ATG: Anti-thymocyte globulin,

CMV: Cytomegalovirus, UTI: Urinary tract infection

It showed that the graft and patient survival rates were similar between the two treatments after 1 year. In the present study, the AR rates were similar to those reported in previous studies for induction therapy with both ATG and basiliximab [18-20]. The incidence of biopsy-proven AR was more than two times greater in the patients who received basiliximab compared with those received ATG $(25.6 \%$ vs. $7.1 \%$, $\mathrm{p}<0.05)$. The severity of rejection was, likewise, more remarkable since the need for antibody treatment was six times greater in the basiliximab cohort than that of the ATG group (18.6\% vs. $2.4 \%$, $\mathrm{p}<0.05$ ). Similarly, according to Brennan et al. [18], the rate of incidence of AR and the severity of rejections were $15.6 \%$ and $1.4 \%$ in the ATG group, respectively, while the incidence of AR $(25.5 \%)$ and that of antibody-treated AR (8\%) were higher in the basiliximab group. Libório et al. [19] also observed a significantly higher incidence of AR and nonsignificantly higher incidence of severe AR in a basiliximab group at the end of a year's follow-up.

The glomerular filtration rate (GFR) was measured using the CockcroftGault formula. It was not significantly different in the two cohorts throughout the study period except on day 7 . The mean GFR at the end of the study was $64.48 \pm 28.24 \mathrm{ml} /$ minute in the ATG group and $60.46 \pm 17.93 \mathrm{ml} /$ minute in the basiliximab group. The renal function was similar in the two groups at the end of 1 year.
Susceptibility to infections, particularly CMV is a complication in patients receiving ATG [21,22]. Brennan et al. observed that the incidence of adverse events and serious adverse events in ATG and basiliximab cohorts $(99.3 \%$ vs. $98.5 \%)$ was similar [18]. In contrast, the present study found a significantly higher incidence of adverse events in the ATG group compared with the basiliximab group (71.4\% vs. $48.3 \%, \mathrm{p}<0.05)$. The incidence of serious adverse events was also higher in the ATG group compared with the basiliximab group albeit the difference was not significant. The present study found a significantly higher incidence of leukopenia in the ATG group compared with the basiliximab cohort. Brennan et al. [18] and Lebranchu et al. [3] found a higher incidence of leukopenia with ATG. However, episodes of thrombocytopenia were not significantly more frequent in the ATC cohort compared with the basiliximab group $(7.15 \%$ vs. $0 \%, \mathrm{p}>0.05)$.

Although ATG and basiliximab were tolerated well in the study population, a greater number of patients had infections in the ATG group (61.9\% vs. $41.8 \%$, p>0.05). Likewise, Yang et al. [20] observed a nonsignificantly high incidence with ATG after a year's follow-up (47.5\% vs. $42.9 \%, p>0.05$ ). Libório et al. [19] found a significantly higher incidence of CMV infections in an ATG group. There was a higher incidence in this ATG cohort despite prophylaxis with ganciclovir, but the difference was not significant. This finding was consistent with that of a study carried out by Yang et al. $[20,23,24]$. In contrast to all these findings, Brennan et al. reported a significantly high incidence in a basiliximab group [18].

The present study had certain limitations. The sample came from a single-center, with the number of participants was limited, and the duration was relatively short.

\section{CONCLUSION}

Although a definite conclusion requires a longer follow-up, the present findings suggest that both strategies were effective in live donor allograft recipients. However, ATG, as compared with basiliximab, was associated with reduced incidence and severity of AR. On the other hand, basiliximab was associated with fewer episodes of adverse events and leukopenia. The two induction therapies had similar graft and patient survival rates.

\section{ACKNOWLEDGMENT}

This work was carried out with support from chairman and medical as well as the paramedical staff of Muljibhai Patel Urological Hospital, Nadiad, Gujarat, India. The authors would also like to acknowledge principal and other staff of Ramanbhai Patel College of Pharmacy, CHARUSAT, Changa, Gujarat, India.

\section{REFERENCES}

1. Cecka JM, Cho YW, Terasaki PI. Analyses of the UNOS scientific renal transplant registry at three years - Early events affecting transplant success. Transplantation 1992;53(1):59-64.

2. Hariharan S, Johnson CP, Bresnahan BA, Taranto SE, McIntosh MJ, Stablein D. Improved graft survival after renal transplantation in the United States, 1988 to 1996. N Engl J Med 2000;342(9):605-12.

3. Lebranchua Y, Bridouxb F, Büchlera M, Le Meurc Y, Etienned I, Toupance $\mathrm{O}$, et al. Immunoprophylaxis with basiliximab compared with antithymocyte globulin in renal transplant patients receiving MMF - Containing triple therapy. Am J Transplant 2002;2:48-56.

4. Kupiec-Weglinski JW, Diamantstein T, Tilney NL. Interleukin 2 receptor-targeted therapy - Rationale and applications in organ transplantation. Transplantation 1988;46(6):785-92.

5. Hariharan S. Long-term kidney transplant survival. Am J Kidney Dis 2001;38 6 Suppl 6:S44-50.

6. Matas AJ, Smith JM, Skeans MA, Thompson B, Gustafson SK Stewart DE, et al. OPTN/SRTR 2013 Annual Data Report: Kidney. Am J Transplant 2015;15 Suppl 2:1-34.

7. Soulillou JP, Cantarovich D, Le Mauff B, Giral M, Robillard N, Hourmant $\mathrm{M}$, et al. Randomized controlled trial of a monoclonal antibody against the interleukin-2 receptor (33B3.1) as compared with rabbit antithymocyte globulin for prophylaxis against rejection of renal 
allografts. N Engl J Med 1990;322(17):1175-82

8. Amlot PL, Rawlings E, Fernando ON, Griffin PJ, Heinrich G, Schreier MH, et al. Prolonged action of a chimeric interleukin-2 receptor (CD25) monoclonal antibody used in cadaveric renal transplantation. Transplantation 1995;60(7):748-56.

9. Brennan DC, Flavin K, Lowell JA, Howard TK, Shenoy S, Burgess S, et al. A randomized, double-blinded comparison of Thymoglobulin versus atgam for induction immunosuppressive therapy in adult renal transplant recipients. Transplantation 1999;67(7):1011-8.

10. Meier-Kriesche HU, Arndorfer JA, Kaplan B. Association of antibody induction with short- and long-term cause-specific mortality in renal transplant recipients. J Am Soc Nephrol 2002;13(3):769-72.

11. Mourad G, Rostaing L, Legendre C, Garrigue V, Thervet E, Durand D. Sequential protocols using basiliximab versus antithymocyte globulins in renal-transplant patients receiving mycophenolate mofetil and steroids. Transplantation 2004;78(4):584-90.

12. Levey AS, Schmid CH, Lau J. Antilymphocyte antibodies, renal trans plantation, and meta-analysis. Ann Intern Med 1998;128:863-5.

13. Meier-Kriesche HU, Ojo AO, Hanson JA, Cibrik DM, Punch JD, Leichtman $\mathrm{AB}$, et al. Increased impact of acute rejection on chronic allograft failure in recent era. Transplantation 2000;70(7):1098-100.

14. Vanrenterghem Y, Lebranchu Y, Hené R, Oppenheimer F, Ekberg H Double-blind comparison of two corticosteroid regimens plus mycophenolate mofetil and cyclosporine for prevention of acute renal allograft rejection. Transplantation 2000;70(9):1352-9.

15. Mourad G, Garrigue V, Squifflet JP, Besse T, Berthoux F, Alamartine E, et al. Induction versus noninduction in renal transplant recipients with tacrolimus-based immunosuppression. Transplantation 2001;72(6):1050-5.

16. Nashan B, Moore R, Amlot P, Schmidt AG, Abeywickrama K, Soulillou JP. Randomised trial of basiliximab versus placebo for control of acute cellular rejection in renal allograft recipients. CHIB 201 International Study Group. Lancet 1997;350(9086):1193-8.

17. Kahan BD, Rajagopalan PR, Hall M. Reduction of the occurrence of acute cellular rejection among renal allograft recipients treated with basiliximab, a chimeric anti-interleukin-2-receptor monoclonal antibody. United States Simulect Renal Study Group. Transplantation 1999;67(2):276-84

18. Brennan DC, Daller JA, Lake KD, Cibrik D, Del Castillo D; Thymoglobulin Induction Study Group. Rabbit antithymocyte globulin versus basiliximab in renal transplantation. N Engl J Med 2006;355(19):1967-77.

19. Libório AB, Mendoza TR, Esmeraldo RM, Oliveira ML, Paes FJ, Silva GB Jr, et al. Induction antibody therapy in renal transplantation using early steroid withdrawal: Long-term results comparing anti-IL2 receptor and anti-thymocyte globulin. Int Immunol 2011;11:1832-6.

20. Yang S, Wang D, Wu W, Lin WH, Xu TZ, Cai JQ, et al. Comparison of single bolus ATG and Basiliximab as induction therapy in presensitized renal allograft recipients receiving tacrolimus-based immunosuppressive regimen. Transpl Immunol 2008;18:281-5.

21. Ducloux D, Kazory A, Challier B, Coutet J, Bresson-Vautrin C, Motte $\mathrm{G}$, et al. Long-term toxicity of antithymocyte globulin induction may vary with choice of agent: A single-center retrospective study. Transplantation 2004;77(7):1029-33.

22. Kaden J, May G, Strobelt V, Groth J, Müller P. Intraoperative T-cell depletion prior to completion of anastomoses by high-dose single ATG bolus as a new approach to improve long-term results after kidney transplantation. Transplant Proc 1997;29(1-2):344-7.

23. Nampoory MR, Abdulhalim M, Johny KV, Al-Jawad Donia FA, Nair MP, Said T, et al. Bolus anti-thymocyte globulin induction in renal transplant recipients: A comparison with conventional ATG or anti-interleukin-2 receptor antibody induction. Transplant Proc 2002;34(7):2916-9.

24. Tullius SG, Pratschke J, Strobelt V, Kahl A, Reinke P, May G, et al. ATG versus basiliximab induction therapy in renal allograft recipients receiving a dual immunosuppressive regimen: One-year results. Transplant Proc 2003;35(6):2100-1. 